\title{
Imaging of the inner structure of cave bear teeth by novel non-destructive techniques
}

\author{
Elisabeth Leiss-Holzinger, Karin Wiesauer, Henrike Stephani, Bettina Heise, \\ David Stifter, Benjamin Kriechbaumer, Stefan J. Spachinger, \\ Christian Gusenbauer, and Gerhard Withalm
}

\begin{abstract}
The potential of non-destructive imaging techniques, such as optical coherence tomography (OCT), X-ray micro-3D computed tomography $(\mu-\mathrm{CT})$ and terahertz $(\mathrm{THz})$ imaging has been considered for structural and age diagnostic tasks in the field of paleontology. In particular OCT, a high-resolution, non-destructive and contactless technology for two and three dimensional (2D, 3D) imaging, was evaluated for the investigation of dental cementum microstructures, exemplified by cave bear teeth. OCT with a depth resolution in the micron range showed its ability to count the annual appositional lines consisting of cementum and thus to determine the age of the individual. As additional method also $\mathrm{THz}$ technology is presented which exhibits much larger penetration depths up to centimeters, but with a lower resolution, in contrast to OCT. Thus, THz imaging gives insight into the internal structure of the cave bear teeth on a larger scale. Furthermore, to complete the variety of considered non-destructive imaging techniques, $\mu$-CT has been applied for analysis of the teeth structures, in comparison to OCT and $\mathrm{THz}$ imaging results. The combination of these complementary methods is well suited for the non-destructive characterization of teeth.
\end{abstract}

Elisabeth Leiss-Holzinger. Research Center for Non-Destructive Testing GmbH, Science Park 2/2.OG, Altenberger Straße 69, 4040 Linz, Austria; elisabeth.leiss@recendt.at Karin Wiesauer. Research Center for Non-Destructive Testing GmbH, Science Park 2/2.OG, Altenberger Straße 69, 4040 Linz, Austria; wiesauer.k@gmail.com Henrike Stephani. Fraunhofer Institute for Industrial Mathematics, Fraunhofer-Platz 1, 67663 Kaiserslautern, Germany; henrike.stephani@itwm.fraunhofer.de Bettina Heise. FLLL at Johannes Kepler University Linz and CDL MS-MACH, Altenberger Strasse 69, 4040Linz, Austria; bettina.heise@jku.at and Research Center for Non-Destructive Testing GmbH, Science Park 2/2.OG, Altenberger Straße 69, 4040 Linz, Austria; bettina.heise@recendt.at

David Stifter. CDL MS-MACH, Altenberger Strasse 69, 4040Linz, Austria; david.stifter@jku.at Benjamin Kriechbaumer. University of Applied Sciences Upper Austria, Linz Campus, Garnisonstraße 21, 4020 Linz, Austria; benjamin.kriechbaumer@gmail.com

Stefan J. Spachinger. University of Applied Sciences Upper Austria, Wels Campus, Stelzhamerstraße 23, 4600 Wels, Austria; no email

PE Article Number: 18.1.1T

Copyright: Palaeontological Association February 2015

Submission: 9 May 2014. Acceptance: 21 January 2015

Leiss-Holzinger, Elisabeth, Wiesauer, Karin, Stephani, Henrike, Heise, Bettina, Stifter, David, Kriechbaumer, Benjamin, Spachinger, Stefan J., Gusenbauer, Christian, and Withalm, Gerhard. 2015. Imaging of the inner structure of cave bear teeth by novel nondestructive techniques. Palaeontologia Electronica 18.1.1T: 1-15. palaeo-electronica.org/content/2015/1058-optical-tomography-comparisons 
Christian Gusenbauer. University of Applied Sciences Upper Austria, Wels Campus, Stelzhamerstraße 23, 4600 Wels, Austria; Christian.Gusenbauer@fh-wels.at

Gerhard Withalm. Institute of Palaeontology, University of Vienna, Althanstraße 14, 1090 Wien, Austria; gerhard.withalm@univie.ac.at

Keywords: tomography optical coherence; imaging; terahertz; X-ray microtomorgraphy; data analysis; tooth (teeth); three-dimensional (3D)

\section{INTRODUCTION}

Being the most durable derivative of bones, teeth are important character complexes, which are used for a wide variety of analyses on taxonomy and evolutionary processes of fossil and extant animals as well (Thenius, 1989). In case of cave bear teeth (Rabeder, 1999), an important fact is that cementum is deposited on the roots, which enables us to distinguish annual increments like in trees (Debeljak, 1996, 2000). The spacings between such annuli vary from the sub-millimeter range to less than $10 \mu \mathrm{m}$. Also other methods exist to determine the age-at-death of bears, based on derivatives such as the skull or the baculum (Withalm and Meng, 2009). But the reliability of all these methods depends on the continuous reconstruction of the corresponding bones, and the latter method is additionally limited to male fossils. Thus, so far for the determination of age-at-death of bears it is mostly necessary to cut off the roots of teeth in order to etch and stain the resulting surface. This leads us to the main advantage of the methods applied in this study, which are contactless and non-destructive: the integrity of the fossil samples is not destroyed.

Nowadays, various methods of non-destructive testing (NDT) with their origin in medicine and material science are applied to investigate paleontological objects, such as confocal, transmission electron and scanning electron microscopy, as well as computed tomography (Schwarz et al., 2005). Depending on their physical principles these methods are limited in terms of resolution or penetration depth as well as size or moisture content of the sample. The comparative application of a variety of techniques including novel approaches is necessary to determine which method or combination of methods is most appropriate for a certain research question. In this work, cave bear teeth were studied by three different non-destructive methods and compared to etched and stained cuts. All three non-destructive methods can provide $2 \mathrm{D}$ or $3 \mathrm{D}$ images of the internal structure of the sample such as voids, inclusions or layered structures.
First, we used the well-established method of $\mathrm{X}$-ray micro-3D computed tomography $(\mu-\mathrm{CT})$. This method visualizes differences in the material composition and density. CT is a common NDT technology in paleontology (Conroy and Vannier, 1984; Britt, 1993; Rowe et al., 2001; Tykoski et al., 2002; Withalm and Meng, 2009), which has become more affordable and reliable within the last 10 years. In addition, $\mu$-CT systems equipped with a matrix detector or $x$-ray camera and a micro-focus tube already work at such high scanning rates that in-vivo 3D scanning with a spatial resolution down to $9 \mu \mathrm{m}$ is possible. Limited by the sample size and the pixel number of the detector, the resolution is typically several micrometers in each direction. It can reach less than 1 micron for small samples and/or a high number of detector pixels. Generally, high resolution imaging demands both, increased scanning time, as well as increased reconstruction time after scanning.

Second, as a novel approach for studying cave bear teeth we applied optical coherence tomography (OCT) (Huang et al., 1991). Initially introduced as a tool for in-vivo diagnostics in biomedicine (Puliafito et al., 1995; Welzel et al., 1997), OCT has meanwhile shown great potential in a large number of different applications ranging from industrial material testing to research in botany (Stifter, 2007), including measurements of teeth (Feldchtein et al., 1998; Colston et al., 2000; Baumgartner et al., 2000; Otis et al., 2000). The optical contrast in OCT is due to heterogeneities in the refractive index of the sample material, thus providing complementary information to the imaging of the sample density by CT. OCT has a typical depth resolution in the range of several micrometers, but a typical penetration depth of less than 3 $\mathrm{mm}$. With its ability to show local changes in the refractive index, OCT was expected to allow for the first time the non-destructive detection of cementum annuli.

As a second novel approach, terahertz ( $\mathrm{THz})$ technology was applied. THz radiation combines several attractive properties with regard to imaging applications: it exhibits large penetration depths in 
TABLE 1. Examined teeth of Ursus ingressus Rabeder et al. (2004) from Gamssulzen cave in Lower Austria (Austria). All specimens are lower first molars (M1) of the right side (dext.) or of the left side (sin.).

\begin{tabular}{lll}
\hline Inv. No. & Side & Remarks \\
\hline GS 26-1 & dext. & Senile, occlusal surface heavily worn on lingual side \\
GS 108-1 & $\sin$. & Adult, occlusal surface slightly worn \\
GS 108-2 & dext. & Subadult, roots not yet closed
\end{tabular}

the centimeter range for many dielectric materials (Jansen et al., 2010), such as polymers, cardboard or ceramics. Due to its longer wavelength $(1 \mathrm{THz}$ corresponds to a wavelength of $300 \mu \mathrm{m}$ ), it exhibits a good spatial resolution down to sub-millimeters compared to the neighboring frequency band of microwaves. Finally, $\mathrm{THz}$ radiation is non-ionizing and thus not hazardous, in contrast to X-rays. The investigation of prehistoric objects seems to be a promising field, as they exhibit low moisture content. High moisture content limits the penetration depth drastically, as $\mathrm{THz}$ radiation is strongly absorbed by water. On the other hand this characteristic absorption can be exploited for sensitively measuring the water content of substances (Castro-Camus et al., 2013). Currently, THz technology is taking the step from being a research-intensive, pure laboratory method to becoming a versatile tool for real-life applications. In the field of archeology, the applicability of $\mathrm{THz}$ imaging has already been demonstrated for the investigation of ancient mummies (Ohrström et al., 2010).

\section{MATERIAL AND METHODS}

The teeth used in this study belong to a member of the cave bear group, Ursus ingressus Rabeder et al. (2004), which inhabited the region between the Black Sea and the Eastern Alps, migrating from East to West until they got extinct approximately 24 ka ago (Rabeder et al., 2004). Teeth of different surface conditions were chosen to test the ability of OCT, all originating from the Gamssulzen cave in Lower Austria (Austria). The material is detailed in Table 1.

Mostly, the cementum annuli of bear teeth are more distinct at the root tip and at a distal thickening near the gum line (Matson, 1981). Thus, sagittal cross-sections give the best information, but also axial cross-sections in the first third down the root. The corresponding cutting and measurement planes with respect to the tooth are pictured in Figure 1. Cross-sectional cutting is less destroying and thus more common in case of the cut, edge and stain method. This method was applied to each specimen after non-destructive testing. All applied non-contact methods, as there were OCT, $\mu-\mathrm{CT}$ and $\mathrm{THz}$, require no preparation of the sample, and the only resolution limiting factor in case of $\mu-C T$ is the size of the sample.

\section{X-ray Computed Tomography}

$\mathrm{X}$-rays are generated inside a vacuum tube by applying high voltage to electrons, which are released by a heated filament (cathode) and accelerated onto a metal target (anode). The collision of electrons with the target material creates X-rays consisting of bremsstrahlung and characteristic radiation. This polychromatic radiation is used to penetrate the specimen. Parts of the X-rays will be absorbed in accordance with Lambert-Beer's law, whereas the transmitted intensity will be captured by a flat panel detector. A set of $2 \mathrm{D}$ projection images is acquired during a full rotation of a specimen, which is finally used to reconstruct 3D images of the specimen consisting of voxels (volumetric pixels). The smaller the sample, the higher is the maximum resolution that can be achieved. X-ray imaging is sensitive to differences in the atomic number $Z$ in the material composition and to the material density (Van Geet et al., 2000).

The measurements were performed applying $X$-ray micro computed tomography $(\mu-C T)$ with a voxel size of $15 \mu \mathrm{m}^{3}$. The object was reconstructed from a series of $17002 \mathrm{D}$ cross section images by filtered backprojection. The rotation of the object can cause typical ring-artifacts in the calculated images. Therefore, the rotation axis of the teeth during measurement was chosen far from the center of the expected annual rings to allow a clear distinction between annual rings and ring artifacts.

\section{Optical Coherence Tomography}

OCT is based on low coherence interferometry and employs broadband light in the near infrared (700-1600 nm) (Bouma and Tearney, 2001). 


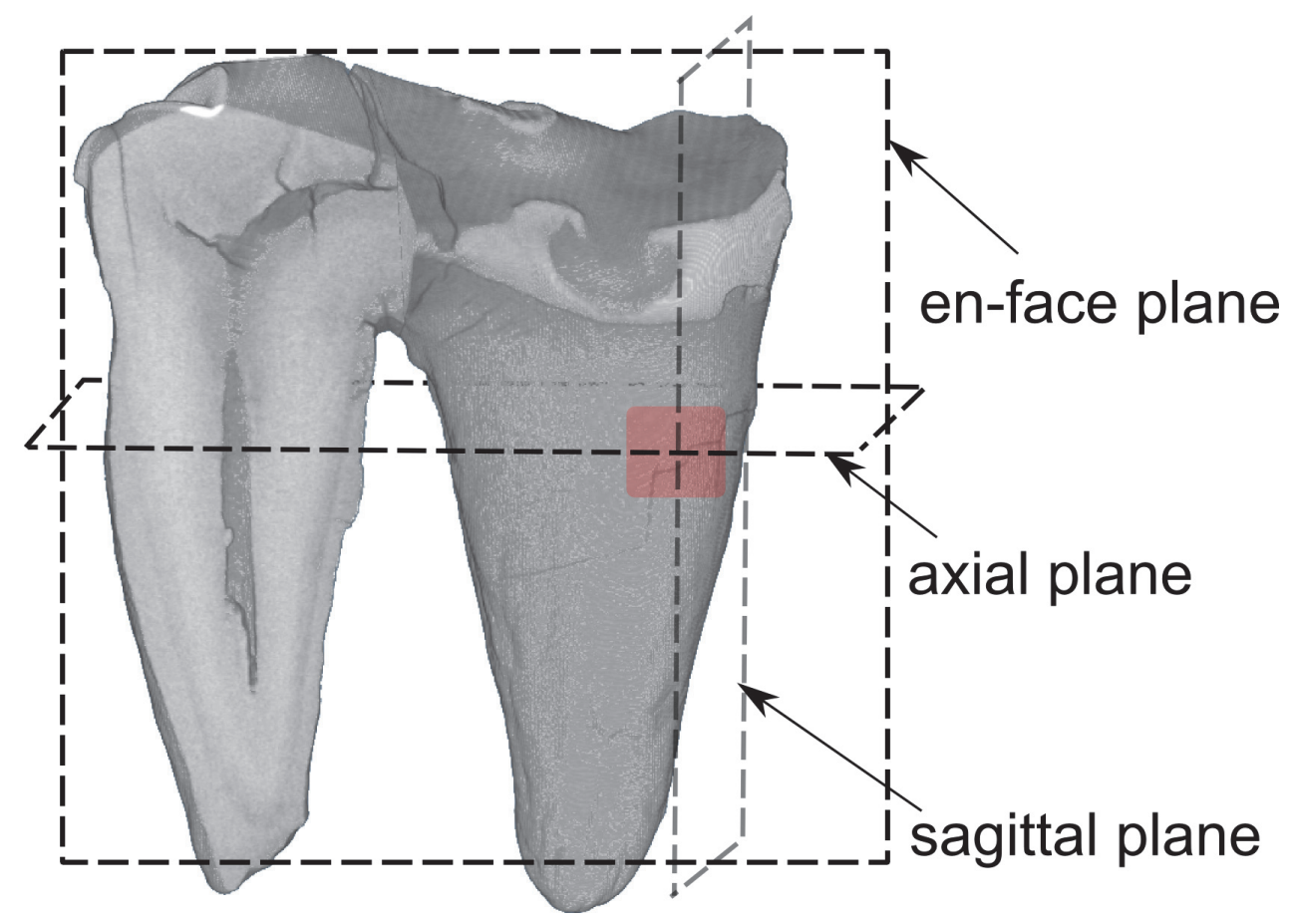

FIGURE 1. Orientation of measurement planes with respect to the tooth. The red area signifies the surface area scanned by OCT.

OCT images are obtained in reflection geometry: The probing light beam is focused into the object and the back-scattered light from different sample structures can be measured in a coherent way. Because of this reflection geometry, OCT mostly detects the interfaces between different materials and delivers therefore contour images, while in $\mu$ CT images different materials are encoded in corresponding grayscale intensities. The lateral and depth (also-called axial) resolutions are decoupled and typically lie in the range of several micrometers. While the lateral resolution is determined by the numerical aperture of the optics, the depth resolution depends on the light source (Brezinski, 2006). For OCT systems the axial resolution is typically more than a factor two better than the lateral resolution. Best depth resolution is achieved for high bandwidth sources centered at shorter wavelengths. On the other hand, systems centered at longer wavelengths often provide a significantly higher penetration depth for highly scattering samples (Stifter, 2007). Generally, the penetration depth of OCT is limited by the absorption and light scattering properties of the sample and is typically less than $3 \mathrm{~mm}$. For 2D and 3D data, the sample is either raster scanned with mirrors and/or moved on a stage. Using mirrors results in high accuracy for high scanning rates, while using a stage allows scanning of large objects of any dimension but on a slower timescale.

For the tooth measurements two different OCT systems were applied. All systems are socalled spectral domain (SD) OCT systems (Fercher et al., 2003; Choma et al., 2003). The broadband spectrum is detected as a whole, which provides an instant axial scan. For our scope, the axial resolution and the penetration depth are the most crucial parameters. To achieve a high axial resolution, the first OCT setup we used was a lab-based system, with a center wavelength around $850 \mathrm{~nm}$ and a spectral width of $260 \mathrm{~nm}$ providing an axial resolution better than $2.6 \mu \mathrm{m}$ in air but less than $1 \mathrm{~mm}$ penetration depth. The lateral resolution is less than $6 \mu \mathrm{m}$. The second one, a commercially available Telesto SD-OCT system from Thorlabs (Lübeck, Germany), with a center wavelength around $1300 \mathrm{~nm}$ and a spectral width of $150 \mathrm{~nm}$, provides a higher penetration depth but only an axial resolution less than $7 \mu \mathrm{m}$ in air. The lateral resolution is less than $15 \mu \mathrm{m}$. For a more detailed description of the systems along with comparative measurements on apples, please refer to (Verboven et al., 2013). In addition, one comparative measurement with our lab-based $1500 \mathrm{~nm}$ polarization sensitive (PS-) OCT system (LeissHolzinger et al., 2012) has been performed. Based 
on the principle of standard photoelasticity (Ramesh, 2000), the so-called polarization sensitive (PS-) OCT (de Boer et al., 1997) technique can yield depth resolved polarization patterns in birefringent samples, such as teeth. With a resolution of $20 \mu \mathrm{m}$ in air, this method has not been applied to detect annual lines, but to show that such polarization patterns cannot be mistaken for annual lines.

OCT images the optical pathway. Therefore the depth of the image is stretched by the factor of the refractive index of the material. While the refractive index in air is 1 , the refractive indices of enamel, dentin and cementum of human teeth at $1310 \mathrm{~nm}$ are about 1.63, 1.54 and 1.58 , respectively (Meng et al., 2009). Assuming a refractive index $\mathrm{n} \sim 1.6$ inside the bear tooth, the axial resolutions of the systems that are in air $2.6 \mu \mathrm{m}$ and $7 \mu \mathrm{m}$, correspond to axial resolutions in material of less than $1.7 \mu \mathrm{m}$ and $4.4 \mu \mathrm{m}$.

\section{THz Technology}

$\mathrm{THz}$ radiation is located in between the infrared (IR) and the microwave band of the electromagnetic spectrum. For the measurements performed in this work, so-called $\mathrm{THz}$ time-domain spectroscopy (THz-TDS) was used (Zhang and Xu, 2010); (Jepsen et al., 2011). For this technique, a short-pulse femtosecond laser was used to excite pulsed $\mathrm{THz}$ radiation from a $\mathrm{THz}$ emitter. The $\mathrm{THz}$ beam was focused onto the sample, and the transmitted $\mathrm{THz}$ radiation was collected by a detector. For imaging, the sample was raster-scanned, and the characteristic time-domain pulse signal was recorded pixel by pixel. By Fourier transform of the time-domain data, a frequency-dependent signal (i.e., spectrum) can be obtained in each pixel. This technique allows determining a quasi "THz-radioscopy" image from the attenuation of the $\mathrm{THz}$ pulse. However, in contrast to a single "x-ray-radioscopy" image, THz-TDS simultaneously delivers a stack of characteristic "THz-radioscopy" images, and socalled hyperspectral images. Each 2D image of this stack corresponds to a certain frequency interval, usually termed channel. Thus, characteristic absorption features due to the chemical composition of the material can be investigated. The time delay of the transmitted $\mathrm{THz}$ pulse can be displayed as additional information, and from the corresponding phase information structural information (e.g., variations in density, inclusions and cavities) can be deduced.

One limiting factor of $\mathrm{THz}$ imaging is still its speed. As an example, as recording of one pixel took about $10 \mathrm{~s}$, imaging of the cave beat tooth (consisting of $80 \times 80$ pixels with an image size of $4 \times 4 \mathrm{~cm}$ ) took about 17 hours. However, several concepts for increasing the speed of $\mathrm{THz}$ measurements are currently evaluated (Zimdars et al., 2010; Jepsen et al., 2011).

\section{RESULTS AND DISCUSSION}

The specimen GS $26-1$ is a lower first molar of the right side (M1 dext.) of a senile Ursus ingressus from Gamssulzen cave in Upper Austria. It shows normal morphological development. Its occlusal surface is heavily worn. The specimen was 3D scanned with the $\mu$-CT system for volume imaging and with the lab-based OCT system at a center wavelength of $\lambda_{c}=850 \mathrm{~nm}$, the system with the highest axial resolution which is better than $2 \mu \mathrm{m}$.

While the volume rendering of $\mu$-CTshows the topography of the whole tooth, OCT provides more detailed information but only about $1 \mathrm{~mm}$ into its subsurface as shown in Figure 2.1. Figures 2 and 3 show a comparison between $\mu-C T$ and OCT data. Three axial cross-sections i)-iii) of the distal root were further analyzed. Figure $2.2-2.4$ shows the corresponding $\mu$-CT data. The regions marked in red are the areas scanned by OCT and are presented in Figure 3.

The images in 3.1 correspond to axial crosssection i) close to the collum dentis, resulting in an outer layer of enamel, which is clearly separated from the underlying dentin. The latter shows no further differentiation. This is true for $\mu$-CT as well as for OCT. Since an OCT interferogram is encoded by the difference in optical path length, the OCT image will be distorted by the refractive index of the specimen. As shown in the magnified detail of the OCT image, the optical path length $\mathrm{p} 1$ through dentin is longer than the true geometric distance that corresponds to the optical path length p2 through air. The factor $\mathrm{p} 1 / \mathrm{p} 2$ correlates to the refractive index 1.49 of dentin, as air has a refractive index of 1 . Thus, the smooth dentin surface shows a "step" in the OCT image, which is an artifact. Generally, the OCT images map the optical pathway, which may result in slight distortions compared to the true geometric dimensions.

The images in Figure 3.2 and 3.3 were taken at the two positions ii) and iii) halfway down the root. In the OCT images the outer perimeter of the root shows a periodic differentiation within cementum. These annuli correspond to a sudden change of the refractive index between cementum formed during winter and cementum formed during the growth seasons of spring and summer. On the 

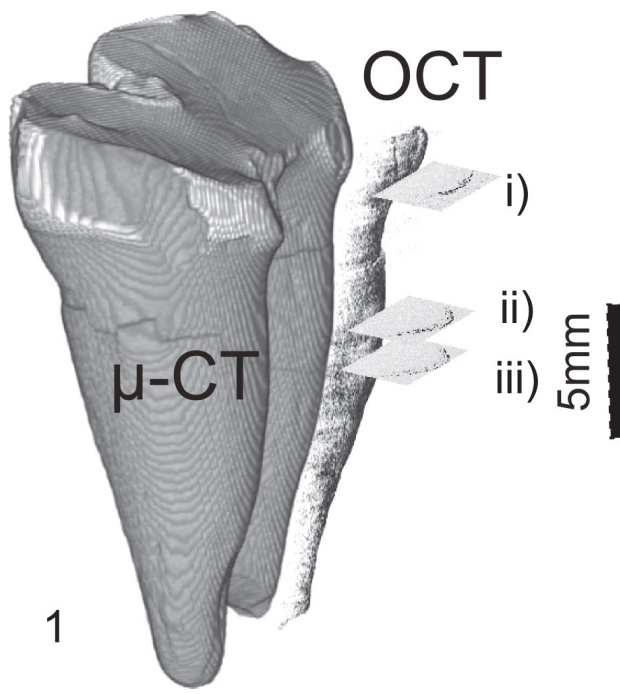

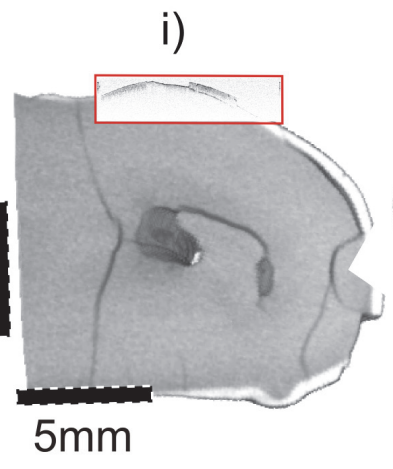

2 ii)

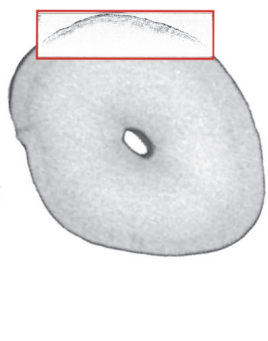

3

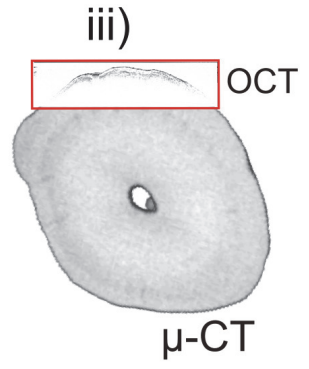

4

FIGURE 2. Specimen GS 26-1. Root of a right lower M1 of a senile individual of Ursus ingressus from Gamssulzen cave (Lower Austria). 2.1. Comparison between $3 \mathrm{D}$ volume rendering of $\mu-C T$ and OCT $\left(\lambda_{C}=850 \mathrm{~nm}\right)$ data. 2.2. - 2.4. Axial cross sections of the mesial root by $\mu$-CT at position i)-iii) as depicted in 2.1 . The regions marked in red show the area scanned by OCT presented in Figure 3.

outer, peripheral surface, some additional deposition is visible, especially in 3.3 . In contrast, in the $\mu$ CT images no inner structure is observed.

In addition, axial cross-sectional OCT images were acquired with the commercial OCT system at $\lambda_{C}=1300 \mathrm{~nm}$. The region scanned with the OCT system is marked in red in the $\mu$-CT volume rendering image in Figure 4.1. In the OCT sectional view in Figure 4.2, the en-face plane shows post mortem cracks in the cementum and a clear interface between dentin and cementum.

The animated $\mu$-CT scan linked in Figure 4.4 captures the whole tooth in constant quality, clearly detecting the enamel and the pulp. In addition, the dentin-cementum interface is visible, at least in the lower part of the tooth as shown in Figure 4.3 and 4.4. In the first axial cross-sectional image of Figure 4.3, the typical ring-artifacts of the $\mu$-CT measurement are highlighted. Anyway, $\mu-C T$ cannot resolve the cementum annuli. In comparison, the animated OCT scan of the en-face images linked in Figure 4.2 starts outside the facial surface of the tooth. Inside the tooth, annuli are visible as vertical lines with their position constantly moved from the center to the left and to the right border. The axial cross sectional scan that follows shows typical variations in the detectability of adjacent annuli, influenced by noise and by little defects in the microstructure. In the course of the scan, the total thickness of the cementum layer decreases and the annuli get closer to each other. Towards the end of the scan the limit of axial resolution is reached and it is no more possible to distinguish single annuli. However, in this region of the tooth near the collum dentis, the cementum/dentin interface is within the penetration depth of the OCT scan and thus visible.

In Figure 5, the $1300 \mathrm{~nm}$ OCT images of all specimens, GS 26-1, GS 108-1 and GS 108-2 are compared to the cuts of the roots. The microscope images of the root cuts show that a dark narrow growth ring forms each winter. Dark blue stain highlights the narrow winter growth for tooth aging analysis (Matson, 1981). The specimen GS 26-1 in Figure 5.1 has been introduced above. As shown in the photo, the distal root has been scanned along a $4 \mathrm{~mm}$ line on its lingual side. The corresponding OCT image reveals the dentin/cementum interface and many cementum annuli, which corresponds to the microscope image. The microscope image shows another section, not of the lingual but of the mesial area of the distal root. In this region the overall thickness of the cementum layers is much higher which helps to distinguish single annuli. This area was not accessible for OCT because the space in between the mesial and distal root was too small for the sensor head. The specimen GS 108-1 (Figure 5.2) is a lower first molar of the left side of an adult and shows normal morphological development. The OCT image and the microscope image both show a single fully developed cementum layer with small point-like material inhomogeneities, acting as centers for light scatterering. Beyond this layer, the typical 


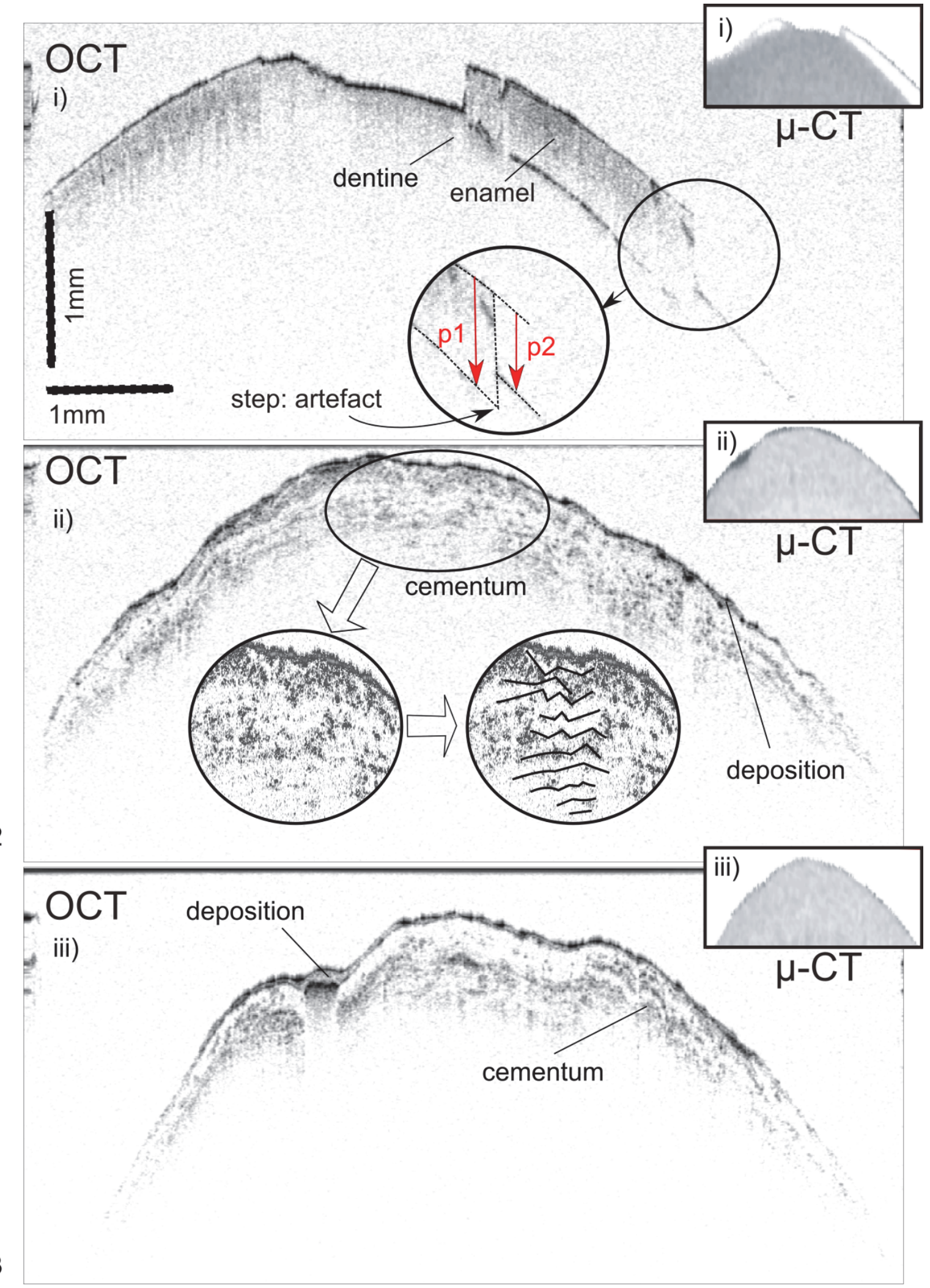

FIGURE 3. Specimen GS $26-1$. Comparison between axial cross-sectional $\mu$-CT and OCT $\left(\lambda_{C}=850 \mathrm{~nm}\right)$ images on the distal root at position i-iii, as depicted in Figure 1. 3.1. The cross section close to the collum dentis shows enamel but no annuli. 3.2.-3.3. The cross-sectional images ii) and iii) show annuli. 

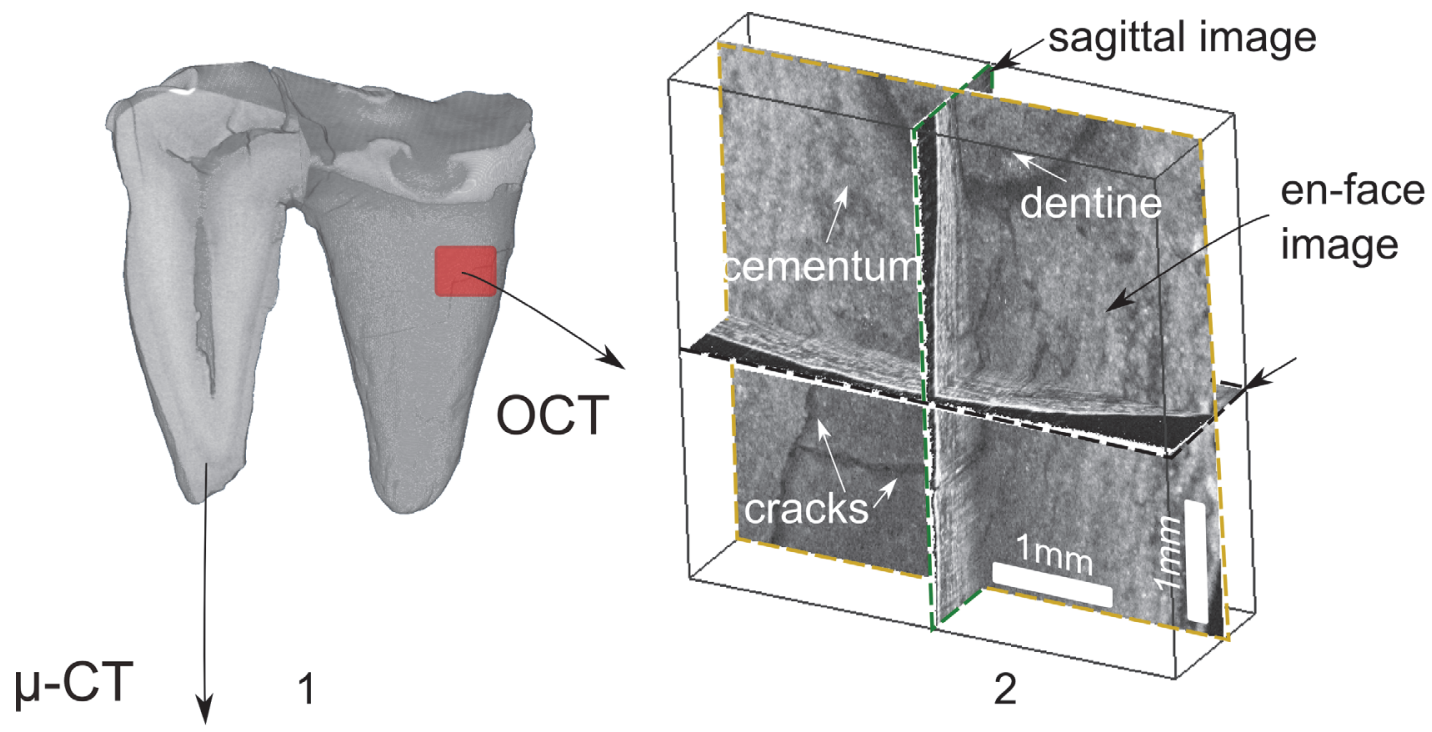

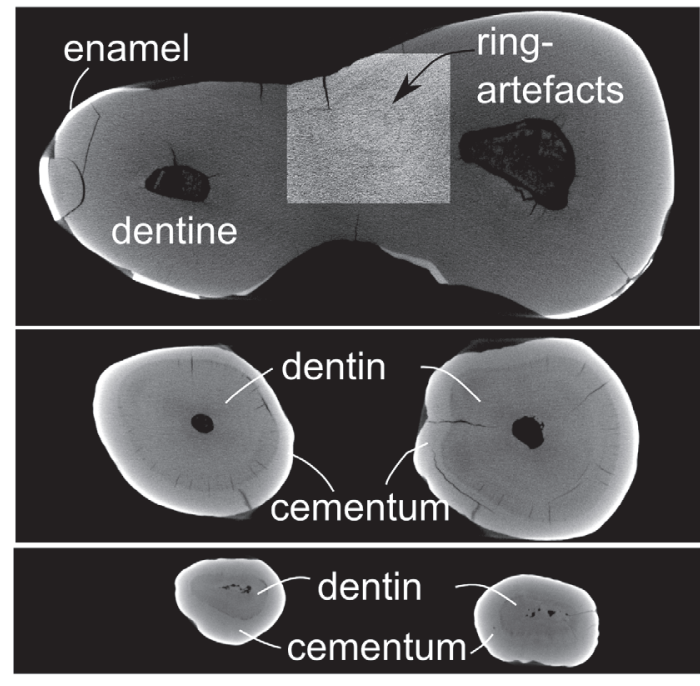

3

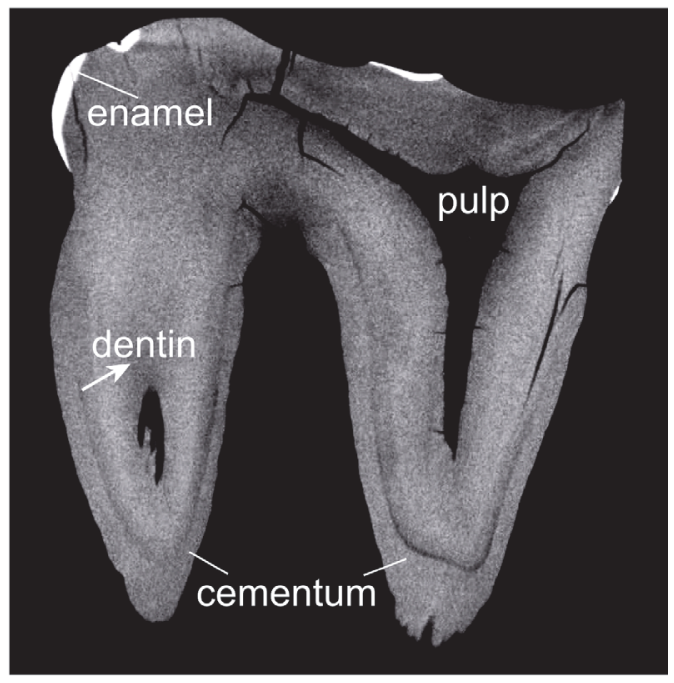

4

FIGURE 4. Specimen GS 26-1. 4.1. Volume rendering of the 3D $\mu$-CT. The red area marks the region scanned by OCT. 4.2. Sectional view of 3D OCT data. Quicktime format video file of animated OCT scan. 4.3. $\mu$-CT axial crosssectional scans and 4.4. $\mu$-CT en-face scan. Quicktime format video file of animated $\mu$-CT scan.

change in color can be observed, representing a single annulus. A new cementum layer just started to grow, which indicates that the bear died within the second year of life. The specimen GS 108-2 (Figure 5.3) is a lower first molar of the right side of a sub-adult and also shows normal morphological development. The roots are not yet closed. This finding is in agreement with both, the OCT image and the microscope image. A first cementum layer had just started to grow which indicates that the bear died within his first year of life.

The quality of the OCT images is always a trade-off between axial resolution and penetration depth. Figure 6 shows the comparison between the commercial system at $1300 \mathrm{~nm}(6.1)$ and the Lab system at $800 \mathrm{~nm}$ (6.2), exemplified by axial cross sections of the specimen GS 108-2 at comparable positions. While the $1300 \mathrm{~nm}$ system offers a high penetration depth and a good contrast of the annual rings, the $800 \mathrm{~nm}$ system is able to resolve structures such as depositions at a finer scale, which is indicated by arrows in Figure 6.2. In addition, a comparative measurement of specimen GS 108-2 with the $1300 \mathrm{~nm}$ system and the polarization sensitive $1500 \mathrm{~nm}$ OCT system has been performed. The polarization patterns marked by arrows in Figure 6.5 are lines of much coarser scale than the annual lines in Figure 6.3. Even in 
Photo

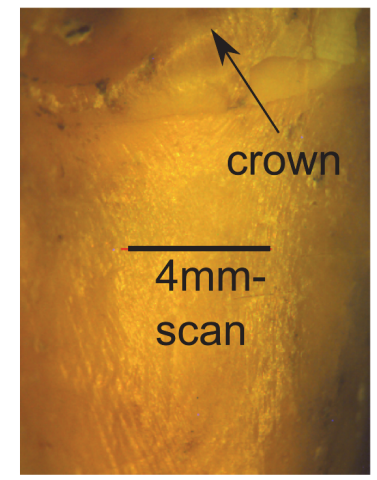

a)

b)

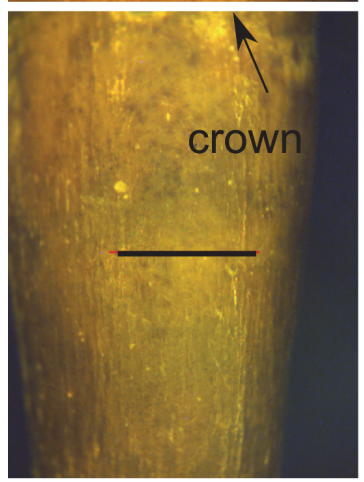

c)

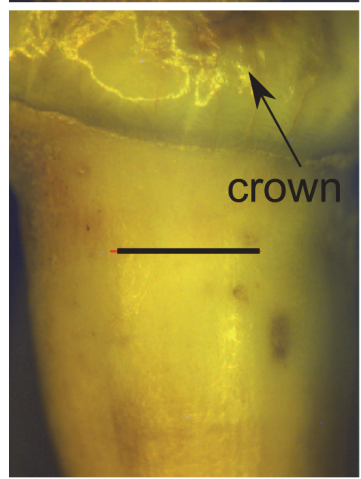

OCT image
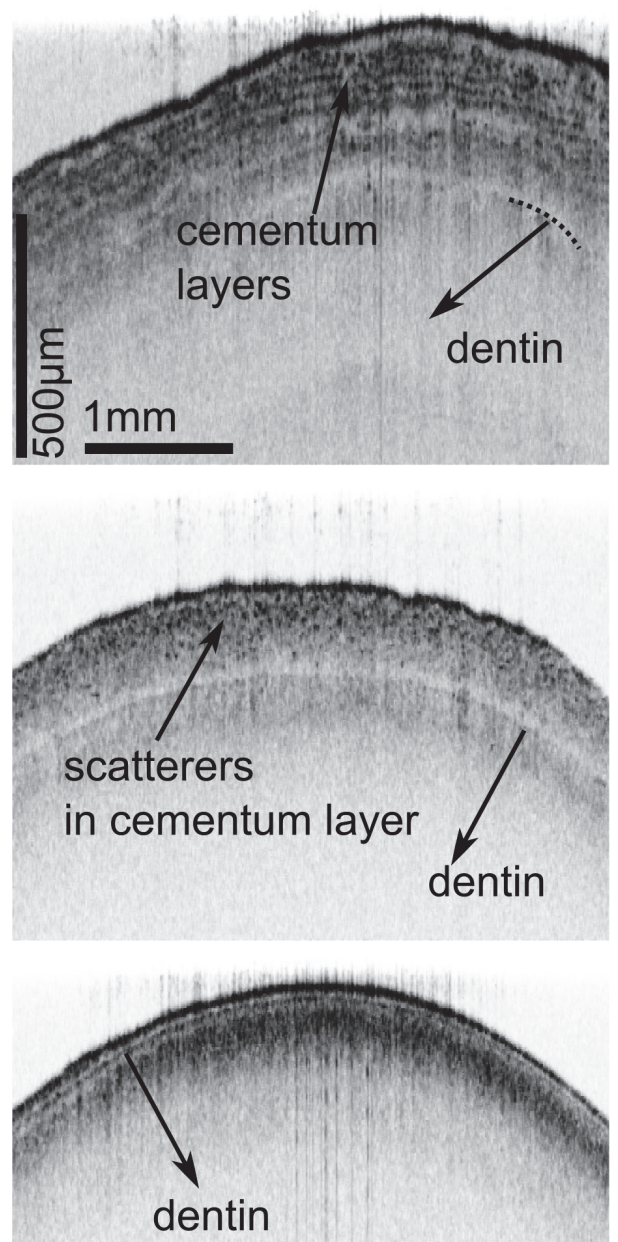

\section{microscope image}
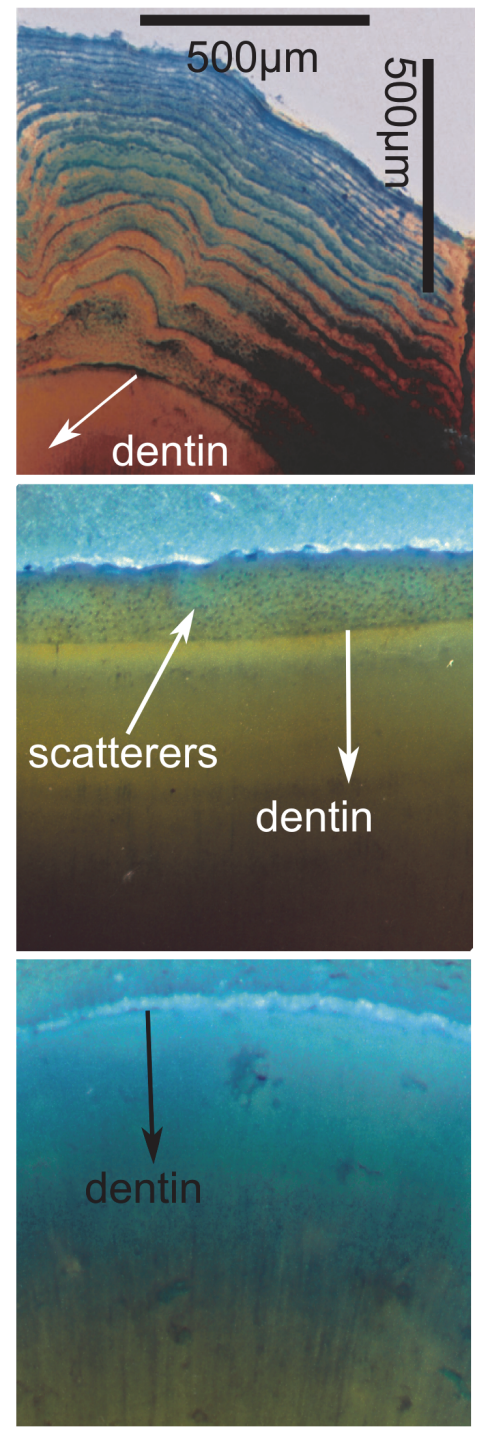

FIGURE 5. Axial cross-sectional OCT image $\left(\lambda_{C}=1300 \mathrm{~nm}\right)$ in the lower third of the tooth radix of specimen. 5.1. GS 26-1 (distal). 5.2. GS 108-1 (mesial). 5.3. GS 108-2 (mesial). The camera images on the left show the OCT scanning region. The OCT images have a lateral dimension of $4 \mathrm{~mm}$. The depth scale bar is stretched according to a refractive index of 1.6, leading to an image depth of about $1 \mathrm{~mm}$. The microscope images are $1 \times 1 \mathrm{~mm}^{2}$ in true aspect ratio. The depth scale of OCT images and microscope image is identical.

case of polarization artifacts, these are most unlikely to be mistaken for annual rings. In addition, the OCT systems at $800 \mathrm{~nm}$ and at $1300 \mathrm{~nm}$ have been tested negative regarding polarization artifacts by imaging a highly birefringent standard sample.

An automated age-at-death evaluation by tooth-cementum annulations, applied to microscope images, has already been introduced in 2006 (Czermak et al., 2006). The results of the automation in comparison to manual inspection have been promising, but the representation of annual rings in OCT images is different. On the microscope images of the stained cuts, the annual rings are mostly represented by continuous lines. In contrast, the OCT images show single points that correspond to local scatterers, aligned along an annual ring. These dotted, discontinuous lines are easy to recognize by the human eye, but, according to our experience, highly challenging for automated data processing. 


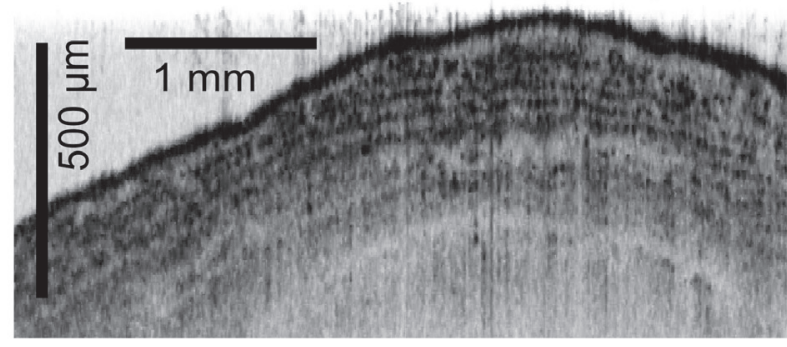

1

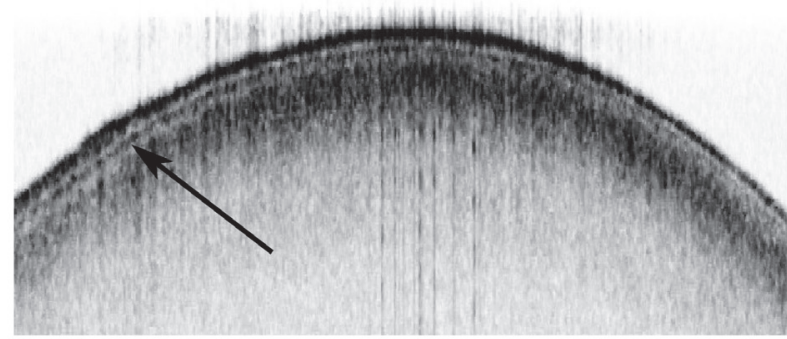

3

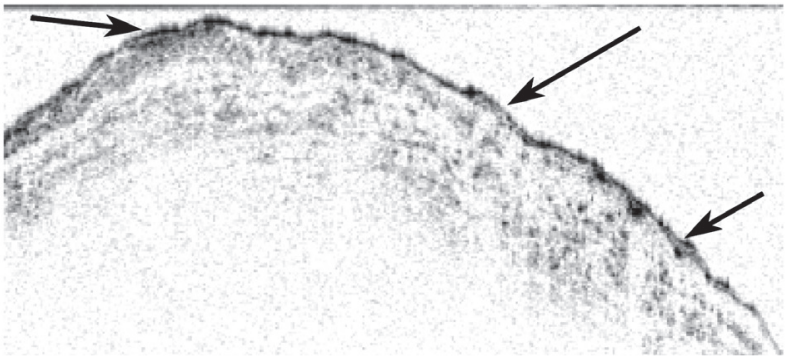

2

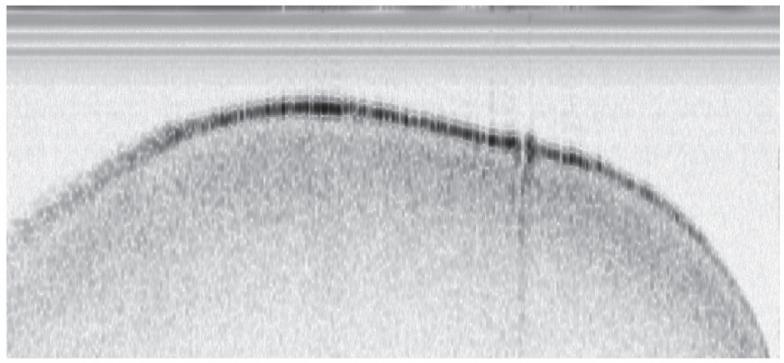

4

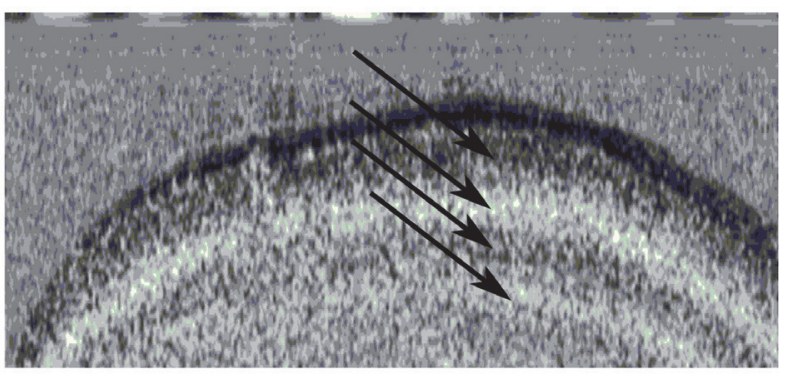

5

FIGURE 6. 6.1-2: Comparison between the commercial system at $1300 \mathrm{~nm}$ (6.1) and the Lab system at $800 \mathrm{~nm}(6.2)$, exemplified by cross-sectional images of the specimen GS 26-1. The arrow in 6.2 indicates a fine structure that cannot be resolved by the $1300 \mathrm{~nm}$ system. 6.3-4: Comparison between the commercial system (6.3) and the PS-OCT system at $1500 \mathrm{~nm}$, exemplified by by cross-sectional images of the specimen GS 108-2. 6.4. shows the reflectivity image, and 6.5. the retardation image. The arrow in 6.3 indicates an annual ring, while the arrows in 6.5 indicate birefringence of the tooth.

In the following, the potential of the THz measurement is presented. Usually, the so-called hyperspectral data set of the $\mathrm{THz}$ pulse is evaluated regarding its spectral information. In the presented measurement this stack corresponds to more than 200 frames recorded at the respective spectral channels. Additionally, overall features, such as the overall absorption/ transmission and the time delay of the whole $\mathrm{THz}$ pulse can be evaluated, corresponding to a single image each. As representative of these overall features, in Figure 7.1 the absorption/ transmission $\mathrm{THz}$ image is shown for specimen GS 108-2. The color map represents the transmitted pulse amplitude. Most absorption is observed in the upper part, i.e., the crown of the tooth. The root canals are visible due to their lower absorption. The structure on bottom of the right root is the holder where the sample was fixed. As a second representative of these overall features, in Figure 7.2 the time delay of the $\mathrm{THz}$ pulses transmitted through the tooth is shown, which is larger in the crown and the sidewalls of the roots due to the higher material thickness compared to the root canals. Thus, in this representation the inner structure of the tooth becomes even more clearly visible.

For comparison, in Figure 7.3 a $\mu$-CT slice of the same specimen is displayed, which shows a good agreement with the $\mathrm{THz}$ measurement. Both imaging methods can visualize the whole tooth and its inner structure. While a better resolution is 


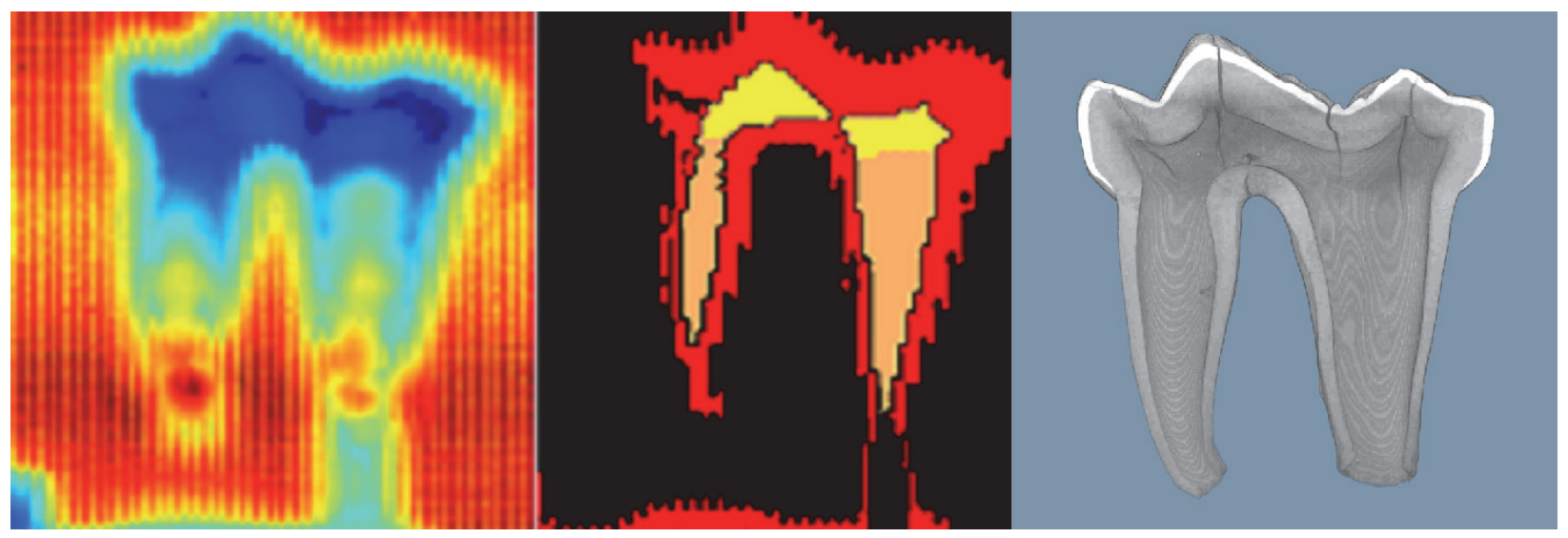

FIGURE 7. Specimen GS 108-2, right lower m1 of a young adult individual of Ursus ingressus from Gamssulzen cave (Lower Austria). Comparison between 7.1. transmitted pulse amplitude, 7.2. time delay of $\mathrm{THz}$ measurement and 7.3. $\mu-\mathrm{CT}$.

achieved by $\mu-\mathrm{CT}$ imaging, $\mathrm{THz}$ imaging is free of the hazard of ionizing radiation.

\section{Image Processing and Clustering}

For such an amount of measured data, the hyperspectral ones and the overall feature data, an appropriate data analysis is required. Information of interest such as absorption peaks is often difficult to identify because it is clouded by other measurement effects occurring due to the thickness of the material for example. Therefore, automatic methods are necessary to reduce these hundreds of frames to a feasible number of representatives that still contain the essential information sought by the measurement.

Wavelets were used as filtering functions to detect significant peaks within the measurement data and accordingly to decrease the amount of data. Due to their good localization properties and their efficient calculation, wavelets are suited for hyperspectral data decomposition to obtain the reduced features set.

The reduced feature set of the presented measurement contains about 16 coefficients (Figure 8.3) instead of more than 200 (Figure 8.1). In addition to the hyperspectral data, overall features (Figure. 8.2), namely the main amplitude, phase slope, phase intercept, echo pulse delay and wavelet scaling factor have been included (Stephani et al., 2010).

To obtain an improved interpretation and classification of hyperspectral data, the previously extracted feature set was automatically classified by means of two clustering approaches:

- A two-step partitional clustering. Based on a k-nearest neighbor graph, which is built on the reduced channel information (Kennel, 2004), the graph is split into segments by a minimum edge cut bi-sectioning method using public software hMETIS, (Karypis and Kumar, 2008). Additionally, foreground background segmentation is performed to downweight information outside of the tooth.

- A pre-clustering-based agglomerative hierarchical clustering. Comparatively an approach including the CHAMELEON algorithm (Karypis et al., 1999), but extended here by a classical agglomerative hierarchical clustering based on pre-cluster representatives with variable distance functions is realized.

Figure 8.4 shows the different domains obtained by two-step partitional clustering approach (with $\mathrm{k}=20$ neighbors). Layer-like structures are discernable within the material, giving a more detailed image of the inner structure of the tooth. The corresponding Quicktime format video file in Figure 8 shows the results of the Preclustering-based agglomerative hierarchical clustering (with 40 clusters and 100 preclusters).

The results of both clustering methods reveal combined information of all data and enable a proper visualization of the extracted content of $\mathrm{THz}$ data under a reduced amount of manual efforts. It should be mentioned that the second approach is more prone to noise, but the first one might suppress information of interest.

For comparison: a Quicktime format video file of the result applying a Preclustering-based agglomerative hierarchical clustering method (40 clusters and 100 preclusters). 

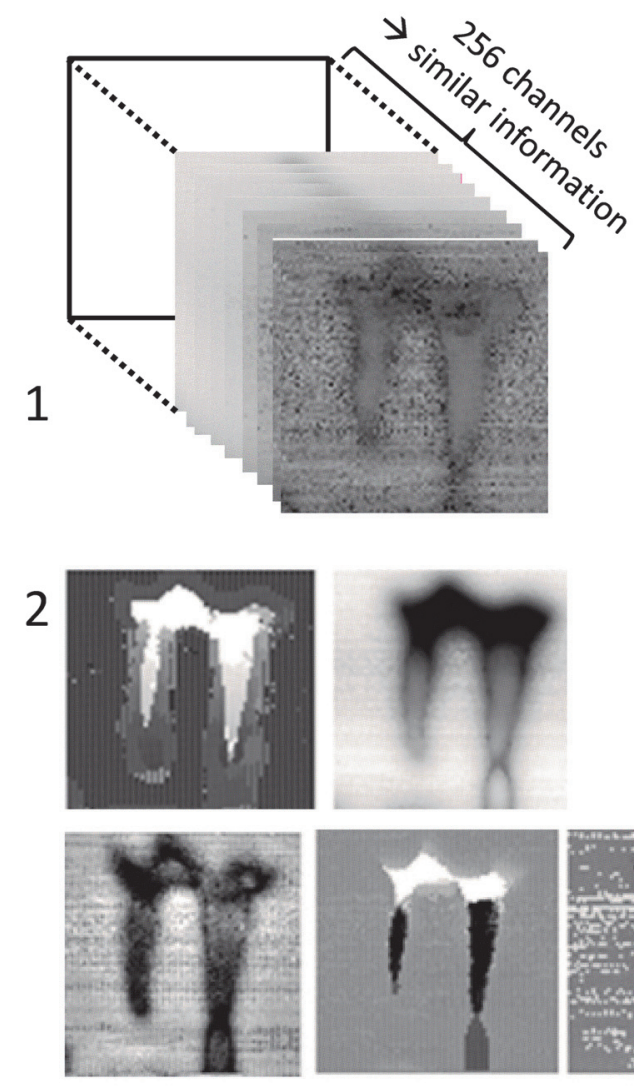

Feature Reduction

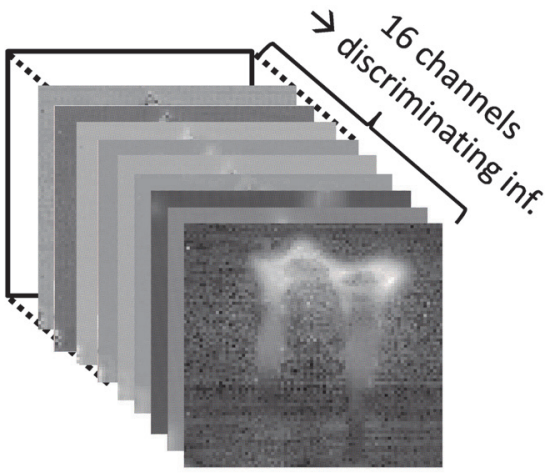

3

Input

Data Set

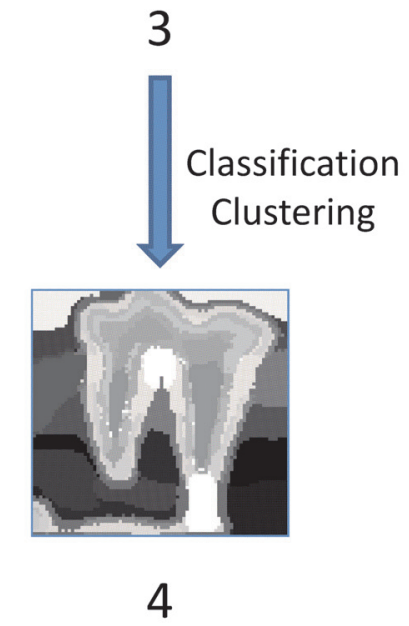

FIGURE 8. Image processing and hyper spectral data analysis: 8.1. Combined input data set containing hyper spectral data; 8.2. Overall features (main amplitude, phase slope, phase intercept, echo pulse delay, wavelet scaling factor); 8.3. Reduced feature set after applying the wavelet based feature reduction method; 8.4. Result of automatic classification by applying the two step partitional clustering method $(\mathrm{k}=20)$ based on the reduced feature set. For comparison: a Quicktime format video file of the result applying a Preclustering-based agglomerative hierarchical clustering method (40 clusters and 100 preclusters).

\section{CONCLUSIONS}

We have demonstrated the ability of $\mu-C T$, OCT and THz imaging as suitable tools for probing and visualizing of the internal structure of cave bear teeth. All these techniques show benefits as they are non-destructive methods and require no special preparation of the specimen. A comparative overview over the applied methods is given in Table 2.

By $\mu-C T$, the structure of the whole tooth can be analyzed in true aspect ratio especially regarding the pulp, cracks and over a large part of the root, also the total thickness of the cementum layer. Towards the gum line, there seems to be less local difference in density between the cementum layer and dentin, because both, OCT and $\mu-C T$, do not image a clear interface. However, $\mu-C T$ is not able to detect cementum annuli, as the resolution is limited by the sample size. However, $\mu$-CT can be an appropriate tool to localize a region of the cementum layer, where the layer thickness doesn't exceed the penetration depth of OCT, but is as thick as possible to clearly distinguish annuli.

OCT as a complementary method has a higher axial resolution and is therefore able to detect the microstructure of the tooth on a finer scale. Obviously, the annual rings of the teeth yield a local change in the refractive index. Thus, beside the detection of small defects and cracks, OCT clearly shows the existence of annual rings and can give a rough estimation within the penetration depth, which is limited by the material composition of the tooth. OCT can be used to count the annual appositional lines and thus to determine the age of the individual without any damage to the fossil. For the age-at-death determination of senile bears the selection of an optimal scanning region is crucial. 
TABLE 2. Comparison between applied measurement methods.

\begin{tabular}{|c|c|c|c|c|}
\hline & Microtome cut & $\mu-C T$ & OCT & $\mathrm{THz}$ \\
\hline & destructive & non-destr. & non-destr. & non-destr. \\
\hline & $2 \mathrm{D}$ & $3 \mathrm{D}$ & $2 D / 3 D$ & $2 D / 3 D$ \\
\hline $\begin{array}{l}\text { Sample } \\
\text { preparation }\end{array}$ & $\begin{array}{l}\text { Cut, edge, } \\
\text { stain }\end{array}$ & No & No & No \\
\hline $\begin{array}{l}\text { Penetration } \\
\text { depth }\end{array}$ & - & $\begin{array}{l}\text { Excellent } \\
100 \%\end{array}$ & $\begin{array}{l}\text { Poor } \\
<2 \mathrm{~mm}\end{array}$ & $\begin{array}{l}\text { Good } \\
\text { several cm }\end{array}$ \\
\hline $\begin{array}{l}\text { Lateral } \\
\text { resolution }\end{array}$ & Excellent & Good & Good & Poor \\
\hline $\begin{array}{l}\text { Axial } \\
\text { resolution }\end{array}$ & - & Good & Excellent & Poor \\
\hline $\begin{array}{l}\text { annual rings } \\
\text { visible }\end{array}$ & Excellent & No & Good & No \\
\hline $\begin{array}{l}\text { spectroscopic } \\
\text { information }\end{array}$ & No & No & No & Yes \\
\hline $\begin{array}{l}\text { Measurement } \\
\text { duration }\end{array}$ & Good & Good & Excellent & Poor-Good \\
\hline hazardeous & No & Ionizing & No & No \\
\hline
\end{tabular}

This implies that at the selected region the cementum is as thick as possible without exceeding the penetration depth, in order to show all layers clearly separated. OCT acquires the optical path. Therefore the images are slightly distorted, but true distances can be estimated if the refractive index is known. The system at a center wavelength of $1300 \mathrm{~nm}$ showed the best compromise regarding resolution versus penetration depth. Generally, a high center wavelength to improve the penetration depth, combined with a higher bandwidth for higher axial resolution would improve the quality of the axial cross-sectional images of the root. Such improvements seem to be within reach by the latest technological developments. An improved quality is crucial for automated age-at-death evaluation by tooth-cementum annulations, based on OCT images. In addition, systems could be equipped with an endoscopic sensor head to give access to narrow scanning regions such as in between the distal and the mesial root. In general OCT provides already more details of the inner structure than conventional $\mu$-CT.

Furthermore, $\mathrm{THz}$ imaging was tested as a new method. It was shown that information regarding the inner structure could be obtained for the whole tooth, providing insights on the different parts of the sample, such as the root canals.

$\mathrm{THz}$ image interpretation can be further eased by applying suitable hyper-spectral image analysis, such as clustering methods, to extract characteristic features. So, for the given application, automatic image processing can support the non-destructive detection of diversities and commonalities between teeth in terms of age, nutrition, etc., by the chemical fingerprint information encoded in $\mathrm{THz}$ data. With a fast $\mathrm{THz}$ set-up, such spectroscopic data could be included in comparative studies, where a large amount of statistical data is required (Rabeder et al., 2008). Compared to $\mu-\mathrm{CT}$, THz 
image resolution is reduced, but only non ionizing radiation is required. With regard to $\mathrm{OCT}, \mathrm{THz}$ imaging can be seen as complementary, as it delivers information with lower resolution, but on a coarser scale with much higher penetration depth.

\section{ACKNOWLEDGMENTS}

This paper acknowledges financial support by the Austrian Science Fund (FWF), project number P19751, the European Regional Development Fund (EFRE) in the framework of the EU-program Regio 13, the federal state of Upper Austria, and by the National Foundation for Research, Technology and Development. Partly, this work was financially supported by the German Federal Ministry of Education and Research (BMBF) via the project HYPERMATH. Additionally, we are indebted to G. Rabeder, who provided us with the material for this study.

\section{REFERENCES}

Baumgartner, A., Dichtl, S., Hitzenberger, C.K., Sattmann, H., Robl, B., Moritz, A., Fercher, A.F. and Sperr, W. 2000. Polarization-sensitive optical coherence tomography of dental structures. Caries Research, 34:59-69. doi:16571.

Bouma, B.E. and Tearney, G.J. 2001. Handbook of Optical Coherence Tomography. Taylor \& Francis.

Brezinski, M.E. 2006. Optical Coherence Tomography: Principles and Applications. Academic Press Inc., Amsterdam; Boston.

Britt, B.B. 1993. Pneumatic Postcranial Bones in Dinosaurs and Other Archosaurs. University of Calgary. Department of Geology and Geophysics.

Castro-Camus, E., Palomar, M. and Covarrubias, A.A. 2013. Leaf water dynamics of Arabidopsis thaliana monitored in-vivo using terahertz time-domain spectroscopy. Scientific Reports, 3: 5pp; http:// www.nature.com/srep/2013/131009/srep02910/full/ srep02910.html doi:10.1038/srep02910.

Choma, M., Sarunic, M., Yang, C. and Izatt, J. 2003. Sensitivity advantage of swept source and Fourier domain optical coherence tomography. Optics Express, 11:2183-2189. doi:10.1364/ OE.11.002183.

Colston, B.W., Everett, M.J., Sathyam, U.S., DaSilva, L.B. and Otis, L.L. 2000. Imaging of the oral cavity using optical coherence tomography. Monographs in Oral Science, 17:32-55.

Conroy, G.C. and Vannier, M.W. 1984. Noninvasive three-dimensional computer imaging of matrix-filled fossil skulls by high-resolution computed tomography. Science, (New York, NY) 226:456-458. doi:10.1126/science.226.4673.456.
Czermak, A., Czermak, A., Ernst, H. and Grupe, G. 2006. A new method for the automated age-at-death evaluation by tooth-cementum annulation (TCA). Anthropologischer Anzeiger; Bericht über die biologisch-anthropologische Literatur, 64:25-40.

Debeljak, I. 1996. A simple preparation technique of cave bear teeth for age determination by cementum increments. Revue de Paléobiologie, Geneve 15(1):105-108.

Debeljak, I. 2000. Dental cementum in the cave bear; comparison of different preparation techniques. Geološki zbornik, 15:25-40.

de Boer, J.F., Milner, T.E., van Gemert, M.J.C. and Nelson, J.S. 1997. Two-dimensional birefringence imaging in biological tissue by polarization-sensitive optical coherence tomography. Optics Letters, 22:934. doi:10.1364/OL.22.000934.

Feldchtein, F., Gelikonov, V., Iksanov, R., Gelikonov, G., Kuranov, R., Sergeev, A., Gladkova, N., Ourutina, M., Reitze, D. and Warren, J. 1998. In vivo OCT imaging of hard and soft tissue of the oral cavity. Optics Express, 3:239-250.

Fercher, A.F., Drexler, W., Hitzenberger, C.K. and Lasser, T. 2003. Optical coherence tomography principles and applications. Reports on Progress in Physics, 66:239. doi:10.1088/0034-4885/66/2/ 204.

Huang, D., Swanson, E., Lin, C., Schuman, J., Stinson, W., Chang, W., Hee, M., Flotte, T., Gregory, K., Puliafito, C. and et, al. 1991. Optical coherence tomography. Science, 254:1178-1181. doi:10.1126/ science.1957169.

Jansen, C., Wietzke, S., Peters, O., Scheller, M., Vieweg, N., Salhi, M., Krumbholz, N., Jördens, C., Hochrein, T. and Koch, M. 2010. Terahertz imaging: applications and perspectives. Applied Optics, 49:48-57.

Jepsen, P.U., Cooke, D.G. and Koch, M. 2011. Terahertz spectroscopy and imaging - Modern techniques and applications. Laser \& Photonics Reviews, 5:124166. doi:10.1002/lpor.201000011.

Karypis, G. and Kumar, V. 2008. hMETIS. Karypis Lab. http://glaros.dtc.umn.edu/gkhome/metis/hmetis/ download

Karypis, G., Han, E.-H. and Kumar, V. 1999. Chameleon: Hierarchical clustering using dynamic modeling. Computer, 32:68-75. doi:10.1109/2.781637.

Kennel, M.B. 2004. KDTREE 2: Fortran 95 and C++ software to efficiently search for near neighbors in a multi-dimensional Euclidean space. arXiv:physics/ 0408067.

Leiss-Holzinger, E., Cakmak, U.D., Heise, B., Bouchot, J.-L., Klement, E.P., Leitner, M., Stifter, D. and Major, Z. 2012. Evaluation of structural change and local strain distribution in polymers comparatively imaged by FFSA and OCT techniques. eXPRESS Polymer Letters, 6:249-256. 
Matson, G.M. 1981. Workbook for Cementum Analysis. Matson's.

Meng, Z., Yao, X.S., Yao, H., Liang, Y., Liu, T., Li, Y., Wang, G. and Lan, S. 2009. Measurement of the refractive index of human teeth by optical coherence tomography. Journal of Biomedical Optics, 14:034010. doi:10.1117/1.3130322.

Ohrström, L., Bitzer, A., Walther, M. and Rühli, F.J. 2010. Technical note: Terahertz imaging of ancient mummies and bone. American Journal of Physical Anthropology, 142:497-500. doi:10.1002/ ajpa.21292.

Otis, L.L., Everett, M.J., Sathyam, U.S. and Colston, B.W. 2000. Optical coherence tomography: a new imaging technology for dentistry. Journal of the American Dental Association, 131:511-514.

Puliafito, C.A., Hee, M.R., Lin, C.P., Reichel, E., Schuman, J.S., Duker, J.S., Izatt, J.A., Swanson, E.A. and Fujimoto, J.G. 1995. Imaging of macular diseases with optical coherence tomography. Ophthalmology, 102:217-229.

Rabeder, G. 1999. Die Evolution des Höhlenbärengebisses. [Evolution of cave bear dentition]. Verlag der Ösrreichischen Akademie der Wissenschaften, Wien.

Rabeder, G., Debeljak, I., Hofreiter, M. and Withalm, G. 2008. Morphological responses of cave bears (Ursus spelaeus group) to high-alpine habitats. Die Höhle, 59:59-72.

Rabeder, G., Hofreiter, M., Nagel, D. and Withalm, G. 2004. New Taxa of Alpine Cave Bears (Ursidae, Carnivora). Cahiers Scientifiques, 2:49-67.

Ramesh, K. 2000. Digital Photoelasticity - Advanced Techniques and Applications. Springer.

Rowe, T., Colbert, M.W., Ketcham, R.A., Maisano, J.A. and Owen, P.R. 2001. High-resolution X-ray computed tomography in vertebrate morphology. Journal of Morphology: 277-278.

Schwarz, D., Vontobel, P., Lehmann, E.H., Meyer, C.A. and Bongartz, G. 2005. Neutron Tomography of Internal Structures of Vertebrate Remains. Palaeontologia Electronica $8.2 .30 \mathrm{~A}: 11 \mathrm{pp}, 1.2 \mathrm{MB}$; palaeoelectronica.org/2005 2/neutron/neutron.pdf
Stephani, H., Leitner, M., Bauer, F. and Heise, B. 2010. Wavelet-based dimensionality reduction for hyperspectral $\mathrm{THz}$ imaging. $\mathrm{THz}$ science and technology: the international journal of THz, 3:117-129.

Stifter, D. 2007. Beyond Biomedicine: A review of alternative applications and developments for optical coherence tomography. Applied Physics B, 88:337-357.

Thenius, E. 1989. Zähne und Gebiss der Säugetiere. [Teeth and denture of mammals]. W. de Gruyter.

Tykoski, R.S., Rowe, T.B., Ketcham, R.A. and Colbert, M.W. 2002. Calsoyasuchus valliceps, a new crocodyliform from the early Jurassic Kayenta formation of Arizona. Journal of Vertebrate Paleontology, 22:593-611. doi:10.1671/02724634(2002)022[0593:CVANCF]2.0.CO;2.

van Geet, M., Swennen, R. and Wevers, M. 2000. Quantitative analysis of reservoir rocks by microfocus $\mathrm{X}$ ray computerised tomography. Sedimentary Geology, 132:25-36. doi:10.1016/S0037-0738(99)00127$\mathrm{X}$.

Welzel, J., Lankenau, E., Birngruber, R. and Engelhardt, R. 1997. Optical coherence tomography of the human skin. Journal of the American Academy of Dermatology, 37:958-963. doi:10.1016/S01909622(97)70072-0.

Withalm, G. and Meng, S. 2009. New insights into the bear skulls from Windener Bärenhöhle (Burgenland, Austria), Abstract Book of the 15th International Cave Bear Symposium, Spišska Nova Vés (Slovakia). https://www.fns.uniba.sk/fileadmin/kalendar/ 2009/symposium/Abstract_book.pdf

Zhang, X.-C. and Xu, J. 2010. Introduction to $\mathrm{THz}$ Wave Photonics. Springer, New York; London.

Zimdars, D., Fichter, G., Megdanoff, C., Murdock, M., Duling, I., White, J. and Williamson, S.L. 2010. Portable video rate time domain terahertz line imager for security and aerospace nondestructive examination. SPIE, 7671, Terahertz Physics, Devices, and Systems IV: Advanced Applications in Industry and Defense, 76710K: 8 pp. doi:10.1117/12.850143. 